\title{
Short Communication Hand pattern indicates prostate cancer risk
}

\begin{abstract}
AA Rahman', A Lophatananon ${ }^{2}$, S Stewart-Brown², D Harriss ${ }^{3}$, J Anderson ${ }^{4}$, T Parker ${ }^{5}$, D Easton ${ }^{6}$, Z Kote-Jarai ${ }^{7}$, R Pocock ${ }^{8}$, D Dearnaley ${ }^{7}$, M Guy $^{7}$, L O'Brien ${ }^{7}$, RA Wilkinson ${ }^{7}$, AL Hall', E Sawyer ${ }^{7}$, E Page ${ }^{7}$, J-F Liu ${ }^{10}$, The UK Genetic Prostate Cancer Study Collaborators ' ', British Association of Urological Surgeons' Section of Oncology ${ }^{\prime \prime}$, RA Eeles ${ }^{7,9,12}$ and K Muir ${ }^{*, 2,12}$

'Division of Epidemiology and Public Health, University of Nottingham, Queens Medical Centre, Nottingham NG7 2UH, UK; ${ }^{2}$ Health Sciences Research Institute, Warwick Medical School, Warwick University, Coventry CV4 7AL, UK; ${ }^{3}$ Nottingham Urology Centre, Nottingham University Hospital NHS Trust, Nottingham NG5 IPB, UK; ${ }^{4}$ Royal Hallamshire Hospital, Glossop Road, Sheffield SI 0 2JF, UK; ${ }^{5}$ School of Biomedical sciences, University of Nottingham, Queens Medical Centre, Nottingham NG7 2UH, UK; ${ }^{6}$ CR-UK Genetic Epidemiology Unit, Strangeways Research Laboratories, Worts Causeway, Cambridge CBI 8RN, UK; ${ }^{7}$ The Institute of Cancer Research, 15 Cotswold Road, Sutton, Surrey SM2 5 NG, UK; ${ }^{8}$ Royal Devon and Exeter NHS Foundation Trust, Barrack Road, Exeter EX2 5DW, UK; ${ }^{9}$ The Royal Marsden NHS Foundation Trust, Downs Road, Sutton SM2 5PT, UK; ${ }^{10}$ Children's Brain Tumour Research, Division of Child Health, University of Nottingham, Queens Medical Centre, Nottingham NG7 2UH, UK
\end{abstract}

BACKGROUND: The ratio of digit lengths is fixed in utero, and may be a proxy indicator for prenatal testosterone levels. METHODS: We analysed the right-hand pattern and prostate cancer risk in 1524 prostate cancer cases and 3044 population-based controls.

RESULTS: Compared with index finger shorter than ring finger (low 2D:4D), men with index finger longer than ring finger (high 2D:4D) showed a negative association, suggesting a protective effect with a $33 \%$ risk reduction (odds ratio (OR) $0.67,95 \%$ confidence interval (Cl) 0.57-0.80). Risk reduction was even greater (87\%) in age group $<60$ (OR 0.13, 95\% Cl 0.09-0.2I). CONCLUSION: Pattern of finger lengths may be a simple marker of prostate cancer risk, with length of $2 \mathrm{D}$ greater than $4 \mathrm{D}$ suggestive of lower risk.

British Journal of Cancer (201 I) 104, I75- 177. doi:10.1038/sj.bjc.6605986 www.bjcancer.com

Published online 30 November 2010

(C) 201 I Cancer Research UK

Keywords: prostate cancer; hand pattern; case-control study

Prostate cancer is the most common non-skin male cancer in the UK (Cancer Research UK, 2010), but current knowledge of its aetiology is limited ( $\mathrm{Li}$ et al, 2004). The ratio of 2 nd and 4 th digit length is fixed in utero (2D:4D ratio), and is sexually dimorphic, lower in men than in women (Lutchmaya et al, 2004; Voracek et al, 2007). To date, only one longitudinal study has investigated digit ratio and prostate volume, PSA level and the prostate cancer risk (Jung et al, 2010). The ratio $(2 \mathrm{D}: 4 \mathrm{D})$ is negatively related to testosterone and related phenotypes, such as sperm counts, and positively related to oestrogen concentrations (Manning and Bundred, 2000). Accordingly, digit length pattern may act as a proxy indicator for the underlying prenatal testosterone levels. We therefore investigated this in a large case - control study of prostate cancer to explore whether there is any association between hand pattern and prostate cancer risk.

\section{MATERIALS AND METHODS}

Information was collected on 1524 non-screen-detected prostate cancer cases and 3044 community-based controls during

\footnotetext{
*Correspondence: Professor K Muir;

E-mail: Kenneth.muir@warwick.ac.uk

1 "Lists available on request.

12 Joint senior authors.

Received 26 July 2010; revised 29 September 2010; accepted 18 October 2010; published online 30 November 2010
}

1994-2009, with eligible cases being men aged $\leqslant 80$ years, currently living in the UK. Prostate cancer cases were identified from three large hospitals, two of them within Trent region in the UK, including Nottingham City Hospital and The Royal Hallamshire Hospitals in Sheffield together with The Royal Marsden NHS Foundation Trust Hospitals, London and Surrey. Controls were recruited via general practitioners of cases who were free of urinary tract symptoms as identified by an International Prostate Symptom Score questionnaire (score of $\leqslant 7$ out of 35 ). A postal questionnaire was sent to all eligible participants to collect information on selected exposures including right-hand pattern. Subjects were asked to identify the finger length pattern on their right hand as nearest to series of pictures, with clear instruction of how best to compare their hand with the pictures provided. There were three illustrations indicating: the index finger longer than the ring finger, the index equally as long as the ring finger and the index shorter than the ring finger. The latter was used as the reference category. The study received ethical committee approval (MREC/99/4/013, 07/MRE04/29).

\section{Statistical analysis}

Unconditional logistic regression (SPSS version 16) was used to generate odds ratios (ORs) and $95 \%$ confidence intervals (CIs). To control for confounding, age and social class were added to the model; age was included as a continuous variable, whereas social class was fitted as a categorical variable. 


\section{RESULTS}

Response rates to the questionnaire for cases and controls were 83 and $70 \%$, respectively. The general characteristics of the study population are shown in Table 1 . The median age of advanced cases is higher than that of the controls (62 compared with 57). Subjects with past smoking history appeared to show a small increase in risk compared with non-smokers (OR 1.20, 95\% CI 1.03-1.39). Social class, education and marital status were not associated with prostate cancer risk (all CIs include 1). More than $90 \%$ of subjects were Caucasian.

Table 2 shows risk estimates for fingers reported to be of approximately equal length and index finger longer than ring finger length and as compared with index shorter than ring finger pattern; the latter reported pattern showing a statistically significant decreased prostate cancer risk with an OR of $0.67 ; 95 \%$ CI $0.57-0.80$.

Table I General characteristics of study population

\begin{tabular}{|c|c|c|c|}
\hline Characteristics & $\begin{array}{l}\text { Advanced cases } \\
(n=1524)\end{array}$ & $\begin{array}{l}\text { Controls } \\
(n=3044)\end{array}$ & $\begin{array}{c}\text { OR (95\% CI } \\
\text { lower-upper) }\end{array}$ \\
\hline Median age & $62(36-80)$ & $57(30-80)$ & $1.09(1.08-1.10)$ \\
\hline \multicolumn{4}{|l|}{ Smoking } \\
\hline Never & $500(32.6)$ & $1104(37.5)$ & 1.00 \\
\hline Ex-smokers & $819(53.4)$ & $1359(44.7)$ & $1.20(1.03-1.39)$ \\
\hline Smokers & $215(14.0)$ & $543(17.9)$ & $1.03(0.84-1.27)$ \\
\hline \multicolumn{4}{|l|}{ Social class ${ }^{\mathrm{a}}$} \\
\hline$|-| \mid$ & 704 (47.3) & I 442 (48.7) & 1.00 \\
\hline$\|I N-\| \mid M$ & $658(44.2)$ & $1319(44.5)$ & $1.07(0.94-1.23)$ \\
\hline $\mathrm{IV}-\mathrm{V}$ & $126(8.5)$ & $200(6.8)$ & $1.15(0.89-1.50)$ \\
\hline \multicolumn{4}{|l|}{ Education } \\
\hline None & $549(36.6)$ & $708(25.2)$ & 1.00 \\
\hline GCSE & $246(16.4)$ & $552(19.6)$ & $0.81(0.66-1.00)$ \\
\hline A level & $91(6.1)$ & $203(7.2)$ & $0.75(0.55-1.01)$ \\
\hline Higher degree & $614(40.9)$ & $1349(48.0)$ & $0.77(0.64-0.92)$ \\
\hline \multicolumn{4}{|l|}{ Marital status } \\
\hline Married & $1246(81.8)$ & 2585 (84.9) & 1.00 \\
\hline Ex-married & $207(13.6)$ & $329(10.8)$ & $1.19(0.97-1.46)$ \\
\hline Single & $71(4.7)$ & $129(4.2)$ & $1.31(0.95-1.81)$ \\
\hline \multicolumn{4}{|l|}{ Ethnicity } \\
\hline White & I 466 (96.4) & $2954(96.9)$ & 1.00 \\
\hline Black & $29(1.9)$ & $33(1.1)$ & $2.40(1.38-4.15)$ \\
\hline Asian & $9(0.6)$ & $40(1.3)$ & $0.59(0.27-1.25)$ \\
\hline Others & $16(1.1)$ & $20(0.7)$ & $1.91(0.91-3.97)$ \\
\hline
\end{tabular}

Abbreviations: $\mathrm{Cl}=$ confidence interval; $\mathrm{GCSE}=$ General Certificate of Secondary Education; OR = odds ratio. ${ }^{\dagger}$ Adjusted for age. ${ }^{a}$ Categories of social class were made by identifying longest held job by participants.

Table 2 Right-hand pattern and prostate cancer risk

\begin{tabular}{lccccr}
\hline $\begin{array}{l}\text { Finger } \\
\text { pattern }\end{array}$ & $\begin{array}{c}\text { Advanced } \\
\text { cases (\%) }\end{array}$ & $\begin{array}{c}\text { Controls } \\
\text { (\%) }\end{array}$ & OR $^{\mathbf{a}}$ & $\begin{array}{c}\mathbf{9 5 \%} \mathbf{~ C l} \\
\text { lower-upper }\end{array}$ & P-value \\
\hline $\begin{array}{l}\text { Index shorter } \\
\text { than ring }\end{array}$ & $872(57.2)$ & $1570(51.6)$ & 1.00 & & \\
$\begin{array}{l}\text { Index equal to ring } \\
\text { Index longer }\end{array}$ & $305(20.0)$ & $538(17.7)$ & 1.05 & $0.88-1.25$ & 0.580 \\
than ring & $347(22.8)$ & $936(30.8)$ & 0.67 & $0.57-0.80$ & $<0.001$ \\
Total & $1524(100.0)$ & $3044(100.0)$ & & & \\
\hline
\end{tabular}

Abbreviations: $\mathrm{Cl}=$ confidence interval; $\mathrm{OR}=$ odds ratio. ${ }^{\mathrm{a}}$ Adjusted for age and socia class.

\section{DISCUSSION}

The study was a large case - control study with data collected over a period of 15 years, with similar rates of cases and controls recruitment. The subjects were asked to self-identify their pattern of index (2D) as compared to ring finger (4D). The results showed a negative association between length of $2 \mathrm{D}$ greater than $4 \mathrm{D}$ and prostate cancer risk (OR $0.67,95 \%$ CI $0.57-0.80)$ in all ages and at ages $<60$ (OR 0.13, 95\% CI 0.09-0.21) (results not shown). These negative associations suspect that lower prenatal activity of testosterone is protective against prostate cancer later in life.

The only study to investigate the relationship between digit length pattern and prostate cancer is the Korean Cohort study (366 subjects), which found a significant negative association between digit ratio and PSA ( $r=-0140, P=0.007)$ (Jung et al, 2010). Those with lower digit ratio had higher mean PSA level and higher risk of prostate biopsy (OR 1.75, 95\% CI 1.07-2.84) and prostate cancer (OR 3.22, 95\% CI 1.33-7.78).

Pictures of the right hand were provided to aid the response as there is a greater sex difference in $2 \mathrm{D}: 4 \mathrm{D}$ on the right hand than on the left hand (Williams et al, 2000). The procedure was particularly successful in terms of response rate $(99 \%$ of eligible subjects responded to the question).

It has been suggested that intrauterine exposure of hormones influences the development of other adult-onset diseases (Manning and Bundred, 2000), including a large study on finger pattern and osteoarthritis risk, in which lower digit ratio was associated with osteoarthritis (Zhang et al, 2008). In the latter study, digit lengths were physically measured on hand radiographs using vernier callipers to achieve a high degree of accuracy and repeatability. This was considered impractical and unethical for our study; hence, hand radiographs were not used. Instead, we used a simpler way to identify the pattern of 2nd and 4th finger by self-reported comparison of the hand with pictures. The self-reported finger length, however, raises the possibility of measurement error, as discussed by Caswell and Manning. In their study, they used two different approaches to measure $2 \mathrm{D}: 4 \mathrm{D}$, including finger length measured from photocopies of the ventral surface of hands (photo 2D:4D) and self-reported finger length measured directly from the finger $(S-R 2 D: 4 D)$. The results suggested that self-reported $2 \mathrm{D}: 4 \mathrm{D}$ showed some more extreme values when compared with photo $2 \mathrm{D}: 4 \mathrm{D}$. It was concluded, however, that a large sample size would reduce the effect size of this (Caswell and Manning, 2009); hence, this possible error is unlikely to have a large effect in our study.

The finger length relationship seen in our study is also in keeping with equivalent studies in breast cancer risk based on current understanding of the role of hormonal patterns in utero. Women with a high ratio of $2 \mathrm{D}: 4 \mathrm{D}$ (indicative of higher prenatal oestrogen exposure) are at greater risk of breast cancer. Women with the more 'feminine' pattern of digit length $(2 \mathrm{D}: 4 \mathrm{D}$ high - ring finger closer in length or shorter than the index finger) were also more likely to present at a younger age (Manning and Bundred, 2000).

Although finger length in humans has been studied for decades, its relationship with hormones has been determined only by one relatively small-scale study (Lutchmaya et al, 2004). In humans, the growth and pattern of digits and the differentiation of gonads is controlled by the homeobox genes HOXA and HOXD. Therefore, gonadal foetal products such as testosterone may influence finger morphology (Manning et al, 2003). For example, a high concentration of testosterone, indicating high prenatal testicular activity leads to low $2 \mathrm{D}: 4 \mathrm{D}$ ratio. The negative correlation between digit ratio and hormone profile has been used as a marker to predict offspring sex ratio and sporting ability (Robinson and Manning, 2000; Williams et al, 2000; Manning and Taylor, 2001; Manning et al, 2002). The ratio (2D:4D) is greater in the right hand than in the left hand, and has a higher sensitivity with foetal androgens 
than the left hand (Williams et al, 2000). A high 2D:4D ratio in male right hands was associated with germ cell failure due to azoospermia or oligospermia with no motility; furthermore, testosterone assays from 58 male subjects were negatively associated with $2 \mathrm{D}: 4 \mathrm{D}$ ratio in the right hand $(P=0.03)$, which was not seen in the left hand (Manning et al, 2000). Twin studies suggest that there is also a possible genetic role in addition to any prenatal environmental influence on this hormonally related skeletal ratio in both men and women (Paul et al, 2006; Gobrogge et al, 2008).

A protective effect of a high $2 \mathrm{D}: 4 \mathrm{D}$ hand pattern on prostate cancer risk was observed. High 2D:4D hand pattern may be the marker of low prenatal androgenic activity, suggesting the importance of hormone modulation in utero on prostate cancer risk. Hand pattern might represent a simple marker for prostate cancer risk, particularly in men age under 60 years.

\section{ACKNOWLEDGEMENTS}

This research was supported by the Prostate Cancer Research Foundation and Cancer Research UK Grant C5047/A8385. We thank The UK Genetic Prostate Cancer Study Collaborators and the British Association of Urological Surgeons' Section of

\section{REFERENCES}

Cancer Research UK (2010) Prostate Cancer Risks and Causes, Vol. 2010. London http://www.cancerhelp.org.uk/type/prostate-cancer/about/prostatecancer-risks-and-causes

Caswell N, Manning JT (2009) A comparison of finger 2D:4D by self-report direct measurement and experimenter measurement from photocopy: methodological issues. Arch Sex Behav 38: 143-148

Gobrogge KL, Breedlove SM, Klump KL (2008) Genetic and environmental influences on 2D:4D finger length ratios: a study of monozygotic and dizygotic male and female twins. Arch Sex Behav 37: 112-118

Jung H, Kim KH, Yoon SJ, Kim TB (2010) Second to fourth digit ratio: a predictor of prostate-specific antigen level and the presence of prostate cancer. BJU Int, E-pub ahead of print; doi: BJU9490 Pii: 10.1111/ j.1464-410X.2010.09490.x

Li H, Stampfer MJ, Giovannucci EL, Morris JS, Willett WC, Gaziano JM, Ma J (2004) A prospective study of plasma selenium levels and prostate cancer risk. J Natl Cancer Inst 96: 696-703

Lutchmaya S, Baron-Cohen S, Raggatt P, Knickmeyer R, Manning JT (2004) 2nd to 4th digit ratios, fetal testosterone and estradiol. Early Hum Dev 77: $23-28$

Manning JT, Barley L, Walton J, Lewis-Jones DI, Trivers RL, Singh D, Thornhill R, Rohde P, Bereczkei T, Henzi P, Soler M, Szwed A (2000) The 2nd:4th digit ratio, sexual dimorphism, population differences, and reproductive success. evidence for sexually antagonistic genes? Evol Hum Behav 21: $163-183$
Oncology for their collaboration on the study. We would also like to thank all men who participated in the study and all the staff in the Urology and Histology Departments from the Nottingham City Hospital, the Sheffield Royal Hallamshire Hospital and the Royal Marsden NHS Foundation Trust. We acknowledge support from the NIHR to the Biomedical Research Centre at the Institute of Cancer Research and Royal Marsden NHS Foundation Trust.

\section{Author contributions}

AA Rahman was involved in conduct of the study, analysing the data and drafting the paper; A Lophatananon was involved in conduct of the study, analysing the data and revising the drafted paper. SS Brown was involved in analysing the data, drafting the paper and approving the final draft. D Harris and J Anderson were involved in set-up of the data collection, approving the study design and revising the final draft. T Parker was involved in revising both the drafted paper and the final draft. D Easton, R Pocock, D Dearnaley, M Guy, Z Kote-Jarai, L O'Brien, RA Wilkinson, AL Hall, E Sawyer, E Page and J-F Liu were involved in development of the protocol, conduct of the study and revision of the paper. R Eeles and K Muir were involved in development of the protocol, conduct of the study, revision of the paper, and were principal investigators and guarantors of this study.

Manning JT, Bundred PE (2000) The ratio of 2nd to 4th digit length: a new predictor of disease predisposition? Med Hypoth 54: 855-857

Manning JT, Callow M, Bundred PE (2003) Finger and toe ratios in humans and mice: implications for the aetiology of diseases influenced by HOX genes. Med Hypoth 60: 340-343

Manning JT, Martin S, Trivers RL, Soler M (2002) 2nd to 4th digit ratio and offspring sex ratio. $J$ Theor Biol 217: $93-95$

Manning JT, Taylor RP (2001) Second to fourth digit ratio and male ability in sport: implications for sexual selection in humans. Evol Hum Behav 22: $61-69$

Paul SN, Kato BS, Cherkas LF, Andrew T, Spector TD (2006) Heritability of the second to fourth digit ratio (2d:4d): a twin study. Twin Res Hum Genet 9: 215-219

Robinson SJ, Manning JT (2000) The ratio of 2nd to 4th digit length and male homosexuality. Evol Hum Behav 21: 333-345

Voracek M, Dressler SG, Manning JT (2007) Evidence for assortative mating on digit ratio (2D:4D), a biomarker for prenatal androgen exposure. J Biosoc Sci 39: 599-612

Williams TJ, Pepitone ME, Christensen SE, Cooke BM, Huberman AD, Breedlove NJ, Breedlove TJ, Jordan CL, Breedlove SM (2000) Fingerlength ratios and sexual orientation. Nature 404: 455-456

Zhang W, Robertson J, Doherty S, Liu JJ, Maciewicz RA, Muir KR, Doherty $M$ (2008) Index to ring finger length ratio and the risk of osteoarthritis. Arthritis Rheum 58: $137-144$ 